\title{
The Relationship between Segmentation and Question Location within Mobile Video Platforms for Enhancing the Ability of Recall
}

\author{
https://doi.org/10.3991/ijim.v13i08.10614 \\ Marwa Zaki Tawfiq Zaki \\ Ain Shams University, Cairo, Egypt \\ dr.marwa.zaki@sedu.asu.edu.eg; drmarwaa_doc@hotmail.com
}

\begin{abstract}
The current research aimed at identifying the relationship between segmentation of video clips (Segmented Video (SV) / Non-Segmented Video (NSV) and Question location (Pre-questions Preq / Post question Postq) through Mobile Video Platforms on affecting the Recall ability among some students of the College of Education. The semi-experimental approach was used as based on the factorial designs $(2 \times 2)$. The research sample consisted of $(63)$ female students from the College of Education at the University of Jeddah and randomly distributed to the four specified research groups. A Recall test has been developed. Analysis of variance (one and two) (ANOVA), Partial Eta Squared, and Schiff's post hoc comparison were employed to analyze data. The results showed the effectiveness of the segmented videos as compared to the non-segmented videos, and of the pre-questions as compared to the post questions, it also showed the priority of the fourth treatment of the interaction between segmented videos and pre-questions locations as compared with other experimental treatments.
\end{abstract}

Keywords-Mobile Video Platform, Segmentation, Question Location, Recall.

\section{$1 \quad$ Introduction}

Mobile Platforms are interactive online services that allow students and teachers have the access to digital content, interactive tools, and online resources to support and manage the learning and teaching process [1,2]. Mobile platforms are also secure educational networks that give teachers simple ways to create and manage classrooms across the web, and provide a productive environment for interaction between teachers and learners, regardless of place or time [3]. Recently, several mobile video platforms have begun to emerge, allowing classrooms to provide the teacher with a variety of strategies that control the presentation of videos, and to offer some interactive features that were not available with video applications deployed across networks over the last few years. Among the technologies provided by Mobile video platforms is the possibility to split up one video for more than one segment in addition to the ability to add various questions within videos [4-6], An example can be at some plat- 
forms available at web and mobile like Edpuzzle (https://edpuzzle.com/), and Educanon platform (http://www.educanon.com/).

Videos are the main component of mobile platforms, but studies related to the examination of technical variables for digital video or the tools associated with these clips did not have the chance to be researched and studies [7]. This is consistent with what has been mentioned in literature that the design process for delivering videos across the web is in general limited and needs further examination and study [8,9]. However, when talking about the video variables that are associated with the mobile video platform system, the segmentation variable becomes one of the most important video variables associated with controlling the pacing of instruction and reducing the excessive cognitive load, leading to the release of knowledge resources and an increase of working memory capacity in encoding new learner information for learners [10]. The principle of segmentation is based on the assumption that the educational program that allows the learner to control the speed of learning through tools that allow him to stop and follow while reading video presentations is more effective than the presentations that run from start to finish without interruption [11]. This is because digital video segmentation gives the learner the opportunity to stop the flow of information when necessary, and allows him to process information more precisely, thus promoting the learning process [12]. Although a large number of studies in literature supported segmented instruction (SI) versus non-segmented instruction (NSI) $[10,13$, 14], the comparison between segmented and non-segmented remains one of the variables that need to be studied within a context that necessitates interaction with other variables [15].

Learning from videos across the web should not only be limited to viewing; however, the viewing process should be linked to a set of questions related to the video content $[16,17]$. Regardless of the number of segments of a video - whether one or several - it is important to determine the best location for the questions that relate with each part of the video. Are the questions located before the beginning of each part? or are they placed at the end of each part? The use of questions within the videos is one of the important variables that need to be studied, especially that it has a strong relationship to the learner's ability to remember and retrieve [18]. Research in studies that focused on the placement of questions, whether before or after the learning content, leads us to the fact that most of the benefits that can be obtained from linking questions to videos comes from studies that have raised questions after viewing the content, while there is little knowledge about the potential benefits of questions being raised before viewing the content, although previous content questions help students encode subsequent information and improve memory performance [19]. In addition, the pre-questions that precede each part of the video may also be important and can be considered as a key tool that guides students to what they will learn and draw their curiosity for learning. It can also be used as a tool for Metacognition [20]. While some believe that pre questions may not enhance or even hamper the learning process because in this case they serve as a selective indicator for the learner's information that the learner should pay attention to what follows in content, thus ignoring other information that are not covered in pre questions [19], others believe that the importance of questions at the end of each part of a video comes as an indicator for hav- 
ing the learner complete watching all the video content and ensure that being exposed to all the key content contained in the clip [16]. It also tests what the learner watches in the videos and helps him apply his new knowledge and however enhance the learning process [21].

The researcher was interested in the groups that handle video as based on segmentation and question location as one of the approaches that aimed at finding solutions to the problem the researcher encountered when teaching the e-learning course for students of the College of Education, especially that the in-classroom learning activities are based on a review of some of the available web-related videos of the course topics, that is followed by a discussion based on the review to the content of these clips. However, the researcher noted an inability to recall the contents of these sections, which are displayed free of charge through some sites and applications that do not have any characteristics based on the segmentation or locating questions, such as (YouTube) and (Vimeo). The researcher went on to try to know the effect of segmentation and the question location in the video clips to enhance the recall capabilities of the students of the College of Education in the e-learning curriculum.

Based on what have been mentioned above, the current research aims to determine the effect of video segmentation (segmentation vs. non-segmentation) and the location of questions through segmented videos, that is, before (prequestion) or after (postquestion) in developing the recall skill within the mobile platforms that are employed in teaching some subjects related to the e-learning course of students of the College of Education, University of Jeddah.

Therefore, the present research attempts to answer the following questions:

- (RQ1) What is the effect of segmenting videos (segmentation vs. nonsegmentation) across mobile platforms in developing the recall skills of students?

- (RQ2) What is the impact of question location within the video (pre-question or post-question) across mobile platforms in developing the recall skills of students?

- (RQ3) What is the impact of the interaction between video segmentation and question location across mobile platforms in in developing the recall skills of students?

- The current research also tries to validate the following hypothesis:

- (H1) There is no statistically significant difference at the level of $\leq 0.05$ between the mean scores of the experimental groups in the post measure of the recall test; due to the effect of segmentation.

- (H2) There is no statistically significant difference at the level of $\leq 0.05$ between the mean scores of the experimental groups in the post measure of the recall test; due to the effect of question location.

- (H3) There is no statistically significant difference at the level of $\leq 0.05$ between the mean scores of the experimental groups in the post measure of the recall test; due to the effect of the interaction between segmentation and question location. 


\section{$2 \quad$ Literature Review}

\subsection{Mobile video platforms}

The e-learning revolution has produced a variety of systems that can be relied on in various learning and teaching processes, including mobile Platforms which have become dependent on unconventional tools in managing educational situations [22, 23]. mobile platforms have become one of the active tools in developing cooperation and creative thinking among learners $[24,25]$, and has proved reliable in the development of student engagement and responsible learning processes $[3,26]$.The design variables of the mobile platforms have also created motivation and stimulation for learners to complete learning tasks [27], and improve learning through active participation in discussions and tasks [27]. Recent popular platforms include video-based platforms, including the edpuzzle platform which succeeded in providing interactive tools such as adding questions in various formats (right and wrong, multiple choice, and open questions). It also allows segmenting video clips so that each clip can handle specific subject area. Other features for these new platforms include anti-skipping to ensure that the student views all the contents of each section of the clip, with a choice that allow the student to re-view specific parts [28]. In addition, these new platforms accept adding subtitles to the clips and using them as a translation bar. They activate content aggregation feature that allow viewing available digital web-based sources next to the video clip through the platform [4].

The main content of the video platforms, which are the video clips themselves, and considering redesigning them so that learners can recall their contents again is an important issue [29]. It is essential for the instructional designer to keep in mind that large videos which exceed 10 minutes may result in the learner not completing the video content [30]. Some cognitive studies have shown that after 10 minutes the learner's stimuli gradually disappear, which means that the learner may not complete the video and then seek new videos immediately [31].

Other studies suggest that it is better to have an average video length of (6) minutes per clip [32]. However, when a video for one lesson is segmented for more than one part, the total parts of all videos should not exceed 20 minutes [33]. In addition, the presence of the teacher in these sections and the use of body language to emphasize some important information increases the student's interest in content areas where a teacher is present [34]. It may also be better to employ tools that allow discussion and comments on the contents of sections that are broadcasted to learners, so that the teacher can support learners who need some guidance when they study outside the classroom and respond to them within a short time rather than waiting for the scheduled class time $[16,35]$.

\subsection{Digital video segmentation}

Video segmentation is based on a premise that these presentations provide fast and continuous information flows, and each flow of information needs to be processed in 
the working memory. Therefore, when not giving the learner enough time to process this information, it is likely that he/she may replace a new information with a previous one regularly without having them stored in the long-term memory [36]. That is why the process of segmentation work to divide the video into successive meaningful clips [37] by adding pauses between these parts that allow the learner to move from one part to another after pressing a follow button [38]. This helps reduce the cognitive load, organize new knowledge, address pre-stop content, control learners' speed of learning, and enable understanding of complex information and content [36, 39-41].

Segmentation also gives learners an opportunity to learn how to extract important information from a specific part before moving on to the next, as well as analyse the visual spatial structure of the content on the screen, which can be difficult to do when the display is constantly changing [42]. Several studies that were interested in segmentation processing versus non-segmentation processing have shown that segmentation process is very effective in developing the ability to acquire knowledge, apply new strategies [10], solving problems [14], enhance performance and conduct cognitive processes [43], and enhance the ability to recall [44].

The segmentation process can be considered as a form of temporal cueing [36], where the segmentation process allows a better focusing on the mini and magnified events within a single video clip [45]. Some have attributed the failure of some digital media - including video - in making a change in learning outcomes to a media design that lacks time organization; this time organization allows the learner to easily process web-based content. This makes segmentation one of the important design factors that should be taken into consideration when designing learning materials, especially that is a key tool that control the timing when processing the educational content [43]. However, segmentation is very important even when the learner does not have control on moving from one part to another withing the digital medium. This was made clear in the study of Spanjers [15] which pointed out that the automatic stop for (2) seconds that is followed by a display of information without any control on the part of the learner has positive results when compared to the display that goes without any stops.

\subsection{Question location within digital video clips}

Examining the optimal placement of questions within digital videos whether before or at the beginning of the segment means looking at the ideal design to employ questions as an instructional tool within the mobile video platforms, rather than simply looking at questions as tools for measurement and evaluation $[19,46]$. This trend and orientation encourage having a good number of mobile video platforms that provide a variety of tools to manage the set of questions across videos [6, 47]. Questions that are presented at the beginning of learning process are called pre-question, while the questions that are presented at the end of the section are referred to as post-questions, and the various positions of the questions in the learning materials have multiple effects on the learners, so it is important to examine the optimal position for the placement of questions with regards to learning outcomes [48]. Some argue that the reliance on pre-questions means simply an activation of the prior knowledge, and an increase of the learners' concentration on the educational materials that will be pre- 
sented later [19], while the post-questions are more related to the idea of retaining the impact of learning and raising the rates of remembrance [49]. Some studies have shown the effectiveness of the instructional materials that are preceded by questions as compared with other educational materials that are not preceded by any questions for memory development $[50,51]$; this can also be found in the study of [19] that targeted a comparison between two groups. First is the experimental and it answered the pre-questions before watching the videos, the second is a control group that watched the videos without pre-questions. The results have shown that the performance of the experimental group was better than the control group, which means that there are positive effects when including pre-questions in videos. While other studies have indicated that there are limited effects of pre-questions; these effects are limited only to information that focused only on pre-questions [52, 53]. As an example, [52] presented a series of multiple-choice questions in three positions, one before explaining the lecture, the second at the end of the lecture, and the third before the unit test. The results indicated an improvement in the performance of students who got prequestions in the two groups, although they did not recall the pre-questioned information in the same way they recall non pre-questioned information. Hence, more than one study has pointed out that a failure to answer pre-questions by learners does not affect the positive advantages that pre-questions offer, especially that their primary role is coding the subsequent information [53,54]. When some criticize the prequestions for their influence in directing the learner to pick only information related to questions [46], it can be noted that video presentations may not face this challenge because they have the ability to control the frequency of information display, allowing the learner to watch all information included in the presentation [46]. Some argue that the post-questions that come at the end of learning processes may have a significant role in improving the understanding of the content of previous questions, especially when these questions focus on inferences and the main ideas that relate to the displayed content, where this kind of question is considered in this case as Adjunct Questions [55]. In a study by [56] that compared the post-questions with the questions generated during learning or learning without questions, the results have shown the effectiveness of the post-questions in improving the efficacy of the recalling skills of the main ideas and factual details.

\subsection{The ability to recall}

The recall is the individual's ability to restore the information stored in his memory, and it is also the ability to remember information when instantly needed [57]. This recall may be a serial recall, in which the material must be remembered in a particular order, and there is also another kind of recall called free recall, through which the information can be brought in any order, and there is also an ordered recall where the learner must recall the words as requested and he/she should identify the sequence or the location of the words that he remembered. Another kind of recall is the caused recall where the learner is given certain information that could help him mention the requested topic, such as the first letter of the word [58-60]. Moreover, recall is one of the components of a broader process called retrieval; it contains two 
major elements: recognition and recall where recognition is a form of memory, and it is easier than the recall because it depends on the existence of previously learnt stimulus. Recognition means that what the individual sees or hears in the present is part of a prior knowledge, while recall is concerned with remembering events and experiences that were learned in the past without an existed stimuli or situations that led to learning [61]. Recall requires two types of activities: first is to search the memory to determine the required information, and second is a simple examination to identify whether the information is familiar or not.

Segmentation can affect the learner's ability to recall information due to the ability of segmentation in organizing the encryption, processing, and storing of information in memory and recalling it from memory. This ultimately affects the memory capacity to perform the recall processes [38]. In addition, questions location significantly affects the ability to recall because pre-questions give indicators for a focus on subsequent content, which means paying more attention and encoding it. On the other hand, post-questions are certainly related to a previously presented information and a training to recall a content that relate to this type of question [52]. The video is also generally an effective tool in addressing the problems of recall as well as its active role in enhancing recall and has great ability to handle the recall errors [62]. The general characteristics of mobile video platforms support anti-oblivion and the ability to recall and remember. According to the decay theory, the main reason for obliviousness is the lack of use or practice of the acquired experience and the theory emphasizes the need to practice and use information from time to time to help retain them and keeping them vivid in memory [63].The mobile video platforms that are based on segmentation and adding question solutions for dealing with obliviousness by allowing the learner to see each part of the content more than once and get trained to recall and encode information more than once, which ultimately enhances the learner's ability to recall $[22,23]$.

\section{Theoretical Framework}

Presenting the content at a rapid pace and in continuous flows without any interruption may exceed the cognitive ability of the learner and thus lead to a cognitive overload [12]. This means that instead of displaying videos in continuous flows, it is better to display them in segments by adding stops within the video through which the learner can moves from one part to another according to his desire and speed in acquiring information [36]. This comes in line with Richard Mayer's Cognitive Theory of Multimedia Learning (CTML) which recognizes the principle of segmentation. It is one of the basic principles of a theory that relates to how information is handled. The principle indicates that learning is best done when presenting content in parts to allow the learner to move between them at his/her own desire rather than continuously displaying them automatically [12]. Working memory performs three things at once: processing information related to external stimuli in working memory, keeping new information in working memory, retrieving information from long-term memory. The working memory capacity is in normal condition limited, and in case the cognitive 
demands of an educational task exceed the memory capacity, it leads to Cognitive Overload. However, using segmentation in this case is one of the solutions through which the amount of information processed by the learner can be controlled without any cognitive overload $[10,44]$.

The Event Segmentation Theory (EST) recognizes an important principle that states that individuals recognize and perceive any activity in the form of separate events through a process called mental segmentation which happens by setting boundaries between events so that current information get perceived, attention processes become organized, and knowledge be stored in the long-term memory. This happens through a procedural process in which the person forms models of the event in his working memory on the basis of sensory information and prior knowledge. Based on these models, predictions are made of what will happen at the next moment and are then compared with what actually happens according to the new sensory information received, and when a difference exists between the expectations and the new sensory received information, a new event model will be constructed for the next part, and in this case the so-called event boundaries are distinguished [64]. There is no doubt that the principle of video clips segmentation provided within the digital video system platforms comes in line with the theory of the event by dividing video clips into separate events which make it easier for the learner process and understand the events' components.

According to Cognitive Load Theory (CLT), the more diverse are the sources of learning and the more varied are the relationships between these sources, the more cognitive burden it puts on the learner, and this makes the subject becomes more difficult in the learning process. However, one of the solutions that must be taken into account to solve such a problem is to provide sufficient time for the learner to be able to handle all elements of learning and draw up relationships between these elements [65].Therefore, segmentation is offered as one of the solutions, which is compatible with the cognitive load theory, in providing the learner with enough time to process web-based educational presentations, which includes a diverse number of educational elements and topics $[36,66]$. It is also important to take into consideration that segmentation may expand the time needed for learning due to the provided pauses through digital videos. However, cognitive load and learning outcomes do not improve with the span of time regardless of how long it is; rather, segmentation is the key factor in improving learning outcomes and in preparing the cognitive load for the learner to receive and process new information. This can be illustrated by Hassler and his colleagues, who have demonstrated the effectiveness of segmentation in all conditions under which the learning time was unified [67].

In normal educational environments, questions and tests are often considered tools for evaluating students' knowledge. It is an annoying event for both students and teaching staff; it is carried out at specific times of the academic year to assess knowledge and efficiency. However, questions are deeper than merely a measure of knowledge, they are effective tools for memory development and retention of what has been learnt; a phenomenon known as testing effect, which in other words mean to what could questions contribute to the survival of the learning effect [49]. Thus, the use of questions within digital stems from a rule that considers questions as a strategy 
to acquire knowledge rather than a test or measure of learners' knowledge, and that the questions as unit is one of the learning events that has an effectiveness in the development of learning outcomes. This effectiveness may go beyond the direct study of a content that does not include any questions [53]. Questions are therefore one of the learning tools, and if any education system has a core set of tools that assist its learning process, questions should be considered as one of the most important tools.

\section{$4 \quad$ Methodology}

\subsection{Design}

This research is based on the semi-experimental approach. It relies on the factorial design $(2 \times 2)$, which is used to measure the effect of independent variables, segmentation, question location on the dependent variable Recall that is related with the study of some of the topics of the e-learning course by the students of the College of Education at the University of Jeddah, and the following table (1) illustrates the experimental design of the research.

Table 1. Research Experimental Design $(2 \times 2)$

\begin{tabular}{|l|l|l|}
\hline & \multicolumn{1}{|c|}{ Segmented video (SV) } & \multicolumn{1}{|c|}{ Non-segmented video (NSV) } \\
\hline $\begin{array}{l}\text { Pre-Questions } \\
\text { (PREQ) }\end{array}$ & $\begin{array}{l}\text { Group (1): A segmented video that con- } \\
\text { sists of five parts; each part is preceded by } \\
\text { questions }\end{array}$ & $\begin{array}{l}\text { Group (2): A video that consists of one part } \\
\text { and preceded by questions }\end{array}$ \\
\hline $\begin{array}{l}\text { Post-questions } \\
\text { (POSTQ) }\end{array}$ & $\begin{array}{l}\text { Group (3): A segmented video that con- } \\
\text { sists of five parts; each part is followed by } \\
\text { questions }\end{array}$ & $\begin{array}{l}\text { Group (4): A video that consists of one part } \\
\text { and followed by questions }\end{array}$ \\
\hline
\end{tabular}

\subsection{Sample}

The current research sample consisted of 63 female students from the College of Education at the University of Jeddah in Saudi Arabia who are studying an "ELearning" course. Students who were good at using the platform and who have the desire to participate were nominated. The selected students were randomly assigned into four groups, (PREQ + SV) which includes (17) students; the second group (PREQ + NSV) and it includes (16) students; the third group (POSTQ + SV) includes (15) students; and the fourth group (POSTQ + NSV) includes also (15) students.

\subsection{Measures}

The research sample students' ability to recall was evaluated by an open-ended test, in which the students answered two main questions, each was divided into four parts, which stimulated the recall of what was explained on the platform. The participants answered each question by writing their answers in each of the four question boxes; each box is allocated to one part of the four question arts. Each student's re- 
sponse was evaluated by two teachers (interrater reliability, $\mathrm{r}=.88$ ). The total value of the recall test scores was (46), which goes as follow: (23) degrees for each question where (3) degrees were assigned for the classification part; (3) degrees for the types part of; (6) degrees were also assigned to the characteristics part; (6) degrees for the tools part; and (5) degrees for the development cycle part. Recall Test Appendix (A)

\subsection{Procedures}

The procedures of the current research have been implemented according to the phases of educational design, specified in (5) basic phases as follows:

\subsection{The analysis phase}

During this phase, the basic to-be implemented task across the mobile video platform in the current research was analyzed. The educational tasks were based on the study of educational platforms and Web 2.0 applications which are one of the main topics of the e-learning course at the College of Education, University of Jeddah.

Each topic covered 5 main themes: concepts, types, characteristics, tools, and development cycle. The characteristics of the sample students were analyzed with regard to the previous use of mobile platforms. $77 \%$ of Students indicated that they use some platforms like Edmodo, and Edpuzzel. In addition, more than one mobile video platform were analyzed, such as Edpuzzel and Educanon, and the Edpuzzel platform was developed because it has all the potentials and characteristics associated with the research variables, and because of the popularity of this platform among the sample students. In addition, this platform (Edpuzzel) has the following features:

- A choice to upload or recall videos from video sharing sites such as YouTube.

- A free download of clips with a capacity of (1) Giga.

- An ability to create more than one chapter, with each having its own independent properties.

- Pauses and segmentation for videos are available.

- Each section can be re-viewed separately.

- A skip feature is available for any part of the video.

- Statistical information about whether or not the student is watching the video, the last time a video was watched, and the total percentage of students completing the video all can be provided.

- A control for the amount of time made available for viewing videos is also available.

- A choice to add questions within your videos and receive answers.

- A choice for sharing video with students through their various accounts.

- A choice to identify the number of students viewing each videos independently.

- A feedback on student inquiries and questions can be provided. 


\subsection{The design phase}

During this stage the video platform and segmentation variables were designed and placed as follows:

Designing Educational Objectives: The educational objectives were based on (10) basic objectives related to the subjects of educational platforms and Web 2.0 applications.

Designing a Presentation for Digital Video: Two visual presentations were designed for educational platforms and Web 2.0 applications, each displaying the five core topics identified in the learning tasks. the learning objectives were also identified in the previous step, then a re-recording of the presentation has been made through one of the screen cam programs (SnagIt), and the video time range has been made not to exceed (10) minutes, so as to guarantee that the learner stay concentrated during the whole period of the video display.

Segmenting the Digital Video Clip: There are two modules for the digital video, which were designed as follows:

Segmenting Video (SV): Video clips were segmented in this module into five parts; each part includes one of the previously mentioned educational subject areas. The balance between these parts was taken into account with regards to time range, and the segmentation was performed using the Add Questions tool within the platform which will be provided with questions - both Pre and Post -in the next stage.

Non-Segmented Videos (NSV): In this processing, the video is played without any segmentation, which means that the video is only made of one part with a duration of 10-minute with no pauses.

Designing Question Location: Post and pre-questions were designed as to have the same formulations, but the only substantive difference between them was in the specific position of each question. The researcher was keen on directing a question for each of the content areas which are identified in five areas.

Designing Pre-question Location: Regarding the position of the pre-question within the segmented videos, a question was added before each of the five parts of the video. Question (1) starts at the first second of part one of the video presentations. In addition, each added pause contain a pre-question of the next part; while for nonsegmented videos, (5) questions were added at the first second of the video presentation.

Designing Post-question Location: Regarding the position of the post-question within the segmented videos, a question was added after each of the five parts of the video. Question (1) starts at the end of pause for part one. In addition, each added pause contains a post-question of the previous part; while for non-segmented videos, (5) questions were added at the end of the last minute (minute 10) of the video presentation. 


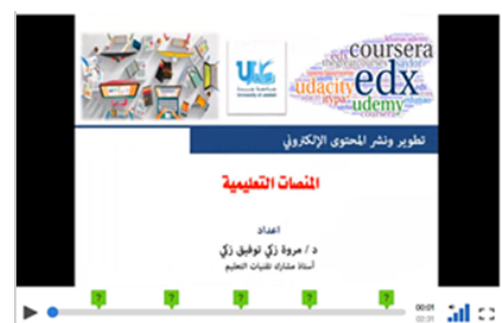

(B): SV+POSTQ

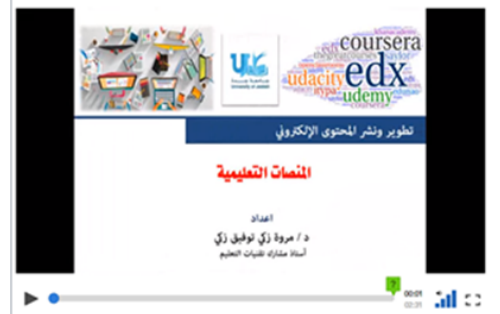

(D): NSV+POSTQ

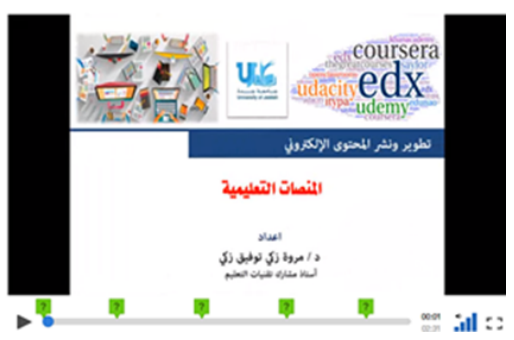

(A): SV+PREQ

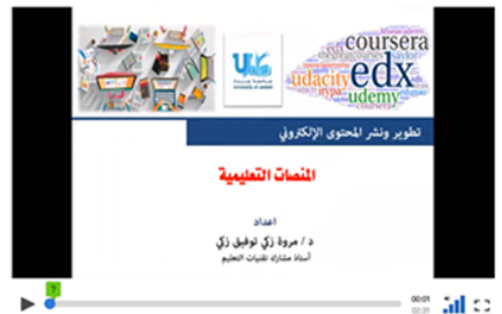

(C): NSV+PREQ

Fig. 1. Illustrates the patterns of video segmentation and question location within the four experimental groups

Figure 1 Segment videos and question locations according to the experimental design

Specify the time period for viewing the video: Using the (Due) tool, one day was only allocated before the final application of the recall test.

Prevent Skipping: The "prevent skipping" option has been activated to prevent skipping of any part of the video before viewing it.

\subsection{The development phase}

At this stage, the teacher's account was activated through the Edpuzzel platform. Four semesters were also created; each one is assigned to an experimental processing. The code of each group was obtained. The structural evaluation of the platform was also carried out.

\subsection{The application phase}

At this stage, the equivalence of the groups was confirmed, the learning process was launched and the tasks performed via the digital video platform, the final postimplementation of the recall test was then carried out. 


\section{$5 \quad$ Results}

The results of the four experimental groups were analyzed for Recall among the research sample students in relation to the Mean Scores and Standard Deviations, and with regards to current search variables, Segmentation and Non-segmentation(SV, NSV), Question location (Preq, Postq) Explains the results of the analysis. Table (2) illustrates the results of the analysis.

Table 2. Mean scores and standard deviations of the four research groups

\begin{tabular}{|l|c|c|c|}
\hline \multirow{2}{*}{ Question location } & \multicolumn{2}{|c|}{ segmentation } & \multirow{2}{*}{ Total } \\
\cline { 2 - 4 } & $\boldsymbol{S} \boldsymbol{N}$ & $\boldsymbol{N} \boldsymbol{V}$ & \\
\hline \multirow{3}{*}{ PREQ } & $\mathrm{Mean}=42.35$ & Mean $=30.94$ & Mean $=36.82$ \\
\cline { 2 - 4 } & $\mathrm{SD}=1.32$ & $\mathrm{SD}=1.95$ & $\mathrm{SD}=6.02$ \\
\cline { 2 - 4 } & $\mathrm{N}=17$ & $\mathrm{~N}=16$ & $\mathrm{~N}=33$ \\
\hline \multirow{3}{*}{ POSTQ } & $\mathrm{Mean}=37.07$ & $\mathrm{Mean}=23.33$ & $\mathrm{Mean}=30.20$ \\
\cline { 2 - 4 } & $\mathrm{SD}=1.33$ & $\mathrm{SD}=1.11$ & $\mathrm{SD}=7.09$ \\
\cline { 2 - 4 } & $\mathrm{N}=15$ & $\mathrm{~N}=15$ & $\mathrm{~N}=30$ \\
\hline \multirow{3}{*}{ Total } & $\mathrm{Mean}=39.88$ & $\mathrm{Mean}=27.26$ & $\mathrm{SD}=33.67$ \\
\cline { 2 - 4 } & $\mathrm{SD}=2.98$ & $\mathrm{SD}=4.17$ & $\mathrm{~N}=63$ \\
\cline { 2 - 4 } & $\mathrm{N}=32$ & $\mathrm{~N}=31$ & \\
\hline
\end{tabular}

The two-way ANOVA was conducted on the students' recall scores according to the segmentation (SV, NSV) and question location (PREQ, POSTQ) to identify significant differences between groups. Table (3) shows the results of two-way ANOVA.

Table 3. The two-way ANOVA on the students' recall scores according to the segmentation and question location

\begin{tabular}{|l|l|l|l|l|l|l|}
\hline \multicolumn{1}{|c|}{ Source } & Sum of Square & \multicolumn{1}{|c|}{ df } & Mean of Square & F & \multicolumn{1}{c|}{ Sig. } & \multicolumn{1}{c|}{ 22 } \\
\hline segmentation & 652.50 & 1 & 652.499 & 302.92 & 0.00 & .837 \\
\hline Question Location & 2483.58 & 1 & 2483.581 & 1153.00 & 0.00 & .951 \\
\hline segmentation* Question location & 21.10 & 1 & 21.098 & 9.70 & 0.00 & 142 \\
\hline Error & 127.09 & 59 & 2.154 & & & \\
\hline Total & 74711.00 & 63 & & & & \\
\hline
\end{tabular}

A summary of the main effects and interactions are presented in the three sections that follow:

\subsection{Effects of video segmentation}

The results have shown that there was significant difference on the main effect for the segmentation $\left[\mathrm{F}_{(1,63)}=302.923, \mathrm{P}=0.00\right]$. Results indicated that $(\mathrm{SV})$ students $[\mathrm{M}=39.88]$ significantly outscored (NSV) $[\mathrm{M}=27.26]$ in the recall scores. When estimating the effect size (Partial Eta Squared) to quantify and explain how much better the effect was, the results showed that the effect size was large for this interaction $(\eta 2=0.837)$, and so this result has practical implications for instructional designers of video. 


\subsection{Effects of question location}

The results have shown that there was significant difference on the main effect for the question location $\left[\mathrm{F}_{(1,63)}=1153.004, \mathrm{P}=0.00\right]$. Results indicated that (Preq) students $[\mathrm{M}=36.82]$ significantly outscored (POSTQ) $[\mathrm{M}=30.20]$ in the recall scores. When estimating the effect size (Partial Eta Squared) to quantify and explain how much better the effect was, the results showed that the effect size was large for this interaction $(\eta 2=0.951)$, and so this result has practical implications for instructional designers of question location.

\subsection{Effects of interaction between the video segmentation and question location}

The interaction between the segmentation and question location has shown significant difference $\left[\mathrm{F}_{(1,63)}=9.795, \mathrm{p}=0.003\right]$. When estimating the effect size (Partial Eta Squared) to quantify and explain how much better the effect was, the results have shown that the effect size was noticeably large for this interaction $(\eta 2=0.142)$. Result of Schiff's post hoc comparison indicated that (SV+PREQ) students [M=42.35] significantly outscored (NSV+PREQ) $[\mathrm{M}=30.94]$ [LSD=11.41, $\mathrm{P}=0.00],(\mathrm{SV}+\mathrm{POSTQ})$ $[\mathrm{M}=37.07][\mathrm{LSD}=5.28, \mathrm{P}=0.00]$ and (NSV+POSTQ) [M=23.33] [LSD=19.02, $\mathrm{P}=0.00]$ students in in the recall scores. Also results showed that (SV+POSTQ) $[\mathrm{M}=37.07]$ significantly outscored (NSV+PREQ) $[\mathrm{M}=30.94]$ [ $\mathrm{LSD}=6.13, \mathrm{P}=0.00]$, and (NSV+POSTQ) $[\mathrm{M}=23.33][\mathrm{LSD}=13.74, \mathrm{P}=0.00]$ in the recall scores. The results have also shown that (NSV+PREQ) [M=30.94] significantly outscored (NSV+POSTQ) $[\mathrm{M}=23.33][\mathrm{LSD}=7.61, \mathrm{P}=0.00]$ in the recall scores.

\section{Discussion}

\subsection{Effects of video segmentation}

The result that indicated the effectiveness of segmentation versus nonsegmentation of digital video in developing recall can be traced back to the ability of segmentation to organize learning subjects, and to place each cognitive unit in its own part; this helped learners understand the details of each part, process it and store it in their memory. The process of segmentation sets a dividing line between each cognitive unit and the unit that follows, thus giving the learner an opportunity to manipulate the content, and not be affected by the successive frequency at which the subsequent presentation can erase what was presented in the previous presentation. The process of segmentation helped to reduce the cognitive burden on learner and free his knowledge resources in a way that helped the sample individuals encode the majority of the information presented in the videos. The process of segmentation thus equipped the learners with greater ability to retrieve the acquired content. The real value of segmentation as compared to non-segmentation lies in the fact that it gives each learner enough time for a flexible handling to all learning contents. So it is the learner 
who decides when to step forward and to what extent he can wait in this part; the learner can also watch the video again and again which is constantly reflected on the learner's recall-related capabilities. The current result is consistent with the cognitive theory of multimedia learning that recognizes the principle of segmentation in which learning is more effective when presenting content in the form of parts as it allows students to move between them. Segmentation rates according to the cognitive theory of multimedia learning may be one of the solutions that help control the amount of information that the learner handles without any additional knowledge burden. This finding is again consistent with was stated in the theory of segmentation, which pointed out that individuals are primarily aware of ongoing information in the form of separate events, and that segmentation gives the learner greater opportunity to deal with the presented events through what is known as mental segmentation. There is a consistency between the result of this research and the results of a large number of studies that targeted segmentation; the results of these studies have shown that segmentation are the best solution for the learner's coding, processing, and retrieve, which is ultimately reflected positively on what is called the recall $[15,36,38,68]$.

\subsection{Effects of question location}

The result that indicated the effectiveness of the placement of pre-questions as compared to post-question in the development of recall ability can be traced back to the fact that the placement of questions initially before viewing the information can provide signs to the cognitive content that must be focused on within the video. This state of alerting to the subsequent content of the videos, which makes the learner in a state of constant attention to search for information that matches the questions presented at the beginning of the content. However, pre-questions in this case act as wake-up stimuli of the coming video content, which makes the learner in a state of constant attention ready to search for information that matches the questions presented at the beginning of the content. In addition, the nature of the place in which the pre-questions are located makes it able to encode the basic themes of information, which makes the learner able to retrieve them again in more than one situation. Prequestions can also be considered as orientation keys to a testable content, which makes the learner highly focused with a content that relates to the presented questions, and thus can easily retrieve it later. Unlike post-questions, pre-questions can be considered as a planning tool for the following learning events and activities. When learners are presented with questions before watching the video, they become in an organized status for all the content details that he/she must learn. Learners' attention is at its highest level at the beginning of any educational situation and it begins to diminish over time. This may explain the strong influence of pre-questions as compared to the post-questions where the learner usually gives less attention to posquestion as compared to pre-questions. In addition, post-questions can be considered as a confirmation of the already raised information and do not have a role in coding knowledge, unlike pre-questions. This finding is consistent with what has been pointed out that pre-testing are effective tools in memory development and aniobliviousness, especially when the learner succeeds in answering these questions. It is 
also a strategy that helps acquire knowledge rather than being an assessment tool for knowledge. This means that pre-testing can be used as a reliable educational tool within videos clips to organize coding, processing and storing information, and then retrieve it again. This result corresponds to previous studies that indicated the effectiveness of pre-testing $[19,50,51,53]$.

\subsection{Effects of interaction between the video segmentation and question location:}

This finding which states that the highest recall rate was for the group that used a segmented video with pre-questions can be traced to the fact the video segmentation helped students organize their learning and gave them the opportunity through various offered pauses to observe what was raised by pre-questions. Pauses also helped students to practice linking pre-questions with what was subsequently presented to them. It can also be said that video segmentation has contributed to enhance appropriating videos for the schematic role that pre-questions play. The success of the group who used video segmentation associated with pre-question over the third group who used segmented videos associated with post-question can be attributed to the fact that the handling done with the third group lacked the guiding and orienting role that prequestions could play; the third group relied on the post-questions that played an affirmative role on prior knowledge. The success of the handling done by the first group over the handling done by the second and fourth groups, which included nonsegmented video clips, can be traced to the fact that the handling of the second and fourth group faced additional cognitive burden because the clips did not have pauses that could enable the learner handle the already presented information and knowledge. The handling done with the second and fourth group lacked having intervals between the main themes of the content which reduced the learner's chances of an in-depth handling for each learning theme.

\section{Conclusion}

The current research focused on some design variables for web-based digital videos. These variables were based on segmentation, question location, and their relation with the recall ability. The research concluded that segmented videos have an advantage over non-segmented videos, pre-questions also have an advantage over postquestions, and that there is an advantage for the handling that includes interactions between segmentation and pre-questions. In the opinion of the research team that future research associated with mobile video platforms may be directed towards studying the relationship between some of the design variables of videos and the cognitive approaches of learners. Due to the importance of the role of the teacher in the process of learning, it is possible to study the degree of the teacher's presence through digital videos. Although the segmentation variable has been studied in more than one study, video segmentation rates still require further studies. Mobile video platforms need to 
be developed so that to become compatible with specific categories of special needs people and addressing this issue is recommended by research orientations.

\section{References}

[1] K.-B. Ooi, J.-J. Hew, and V.-H. Lee, "Could the mobile and social perspectives of mobile social learning platforms motivate learners to learn continuously?," Computers \& Education, vol. 120, pp. 127-145, 2018/05/01/ 2018. https://doi.org/10.1016/j.compedu.2018.01 .017

[2] A. A. Zeidan, W. S. Alhalafawy, and M. Z. Tawfiq, "The Effect of (Macro/Micro) Wiki Content Organization on Developing Metacognition Skills," Life Science Journal, vol. 14, p. 12, 2017.

[3] K. Balasubramanian, V. Jaykumar, and L. N. Fukey, "A Study on "Student Preference towards the Use of Edmodo as a Learning Platform to Create Responsible Learning Environment"," Procedia - Social and Behavioral Sciences, vol. 144, pp. 416-422, 2014/08/20/ 2014. https://doi.org/10.1016/j.sbspro.2014.07.311

[4] A. Kleftodimos and G. Evangelidis, "An interactive video-based learning environment supporting learning analytics: Insights obtained from analyzing learner activity data," in State-of-the-Art and Future Directions of Smart Learning, ed: Springer, 2016, pp. 471-481. https://doi.org/10.1007/978-981-287-868-7_56

[5] S. Rabidoux and A. Rottmann, "Re-envisioning the Archaic Higher Education Learning Environment: Implementation Processes for Flipped Classrooms," International Journal on E-Learning, vol. 17, pp. 85-93, 2018.

[6] C. C. Shelton, A. E. Warren, and L. M. Archambault, "Exploring the use of interactive digital storytelling video: Promoting student engagement and learning in a university hybrid course," TechTrends, vol. 60, pp. 465-474, 2016. https://doi.org/10.1007/s11528-016$\underline{0082-\mathrm{Z}}$

[7] C.-L. Lai and G.-J. Hwang, "A self-regulated flipped classroom approach to improving students' learning performance in a mathematics course," Computers \& Education, vol. 100, pp. 126-140, 2016/09/01/ 2016. https://doi.org/10.1016/j.compedu.2016.05.006

[8] Y.-T. Chien and C.-Y. Chang, "Comparison of different instructional multimedia designs for improving student science-process skill learning," Journal of Science Education and Technology, vol. 21, pp. 106-113, 2012. https://doi.org/10.1007/s10956-011-9286-3

[9] M. Merkt, S. Weigand, A. Heier, and S. Schwan, "Learning with videos vs. learning with print: The role of interactive features," Learning and Instruction, vol. 21, pp. 687-704, 2011. https://doi.org/10.1016/j.learninstruc.2011.03.004

[10] D. L. Lusk, A. D. Evans, T. R. Jeffrey, K. R. Palmer, C. S. Wikstrom, and P. E. Doolittle, "Multimedia learning and individual differences: Mediating the effects of working memory capacity with segmentation," British Journal of Educational Technology, vol. 40, pp. 636-651, 2009. https://doi.org/10.1111/j.1467-8535.2008.00848.x

[11] R. E. Mayer and P. Chandler, "When learning is just a click away: Does simple user interaction foster deeper understanding of multimedia messages?," Journal of educational psychology, vol. 93, p. 390, 2001. https://doi.org/10.1037//0022-0663.93.2.390

[12] R. E. Mayer, The Cambridge handbook of multimedia learning: Cambridge university press, 2005.

[13] H. Hassanabadi, E. S. Robatjazi, and A. P. Savoji, "Cognitive consequences of segmentation and modality methods in learning from instructional animations," Procedia-Social and 
Behavioral Sciences, vol. 30, pp. 1481-1487, 2011. https://doi.org/10.1016/j.sbspro.2011. 10.287

[14] H. K. Tabbers and B. de Koeijer, "Learner control in animated multimedia instructions," Instructional Science, vol. 38, pp. 441-453, 2010. https://doi.org/10.1007/s11251-0099119-4

[15] I. A. E. Spanjers, P. Wouters, T. van Gog, and J. J. G. van Merriënboer, "An expertise reversal effect of segmentation in learning from animated worked-out examples," Computers in Human Behavior, vol. 27, pp. 46-52, 2011/01/01/ 2011. https://doi.org/10.1016/j.chb.20 $\underline{10.05 .011}$

[16] A. Fidalgo-Blanco, M. Martinez-Nuñez, O. Borrás-Gene, and J. J. Sanchez-Medina, "Micro flip teaching-An innovative model to promote the active involvement of students," Computers in Human Behavior, vol. 72, pp. 713-723, 2017. https://doi.org/10.1016/j.chb. $\underline{2016.07 .060}$

[17] C. K. Lo, C. W. Lie, and K. F. Hew, "Applying "First Principles of Instruction" as a design theory of the flipped classroom: Findings from a collective study of four secondary school subjects," Computers \& Education, vol. 118, pp. 150-165, 2018/03/01/ 2018. https:// doi.org/10.1016/j.compedu.2017.12.003

[18] S. K. Carpenter, S. Rahman, and K. Perkins, "The effects of prequestions on classroom learning," Journal of Experimental Psychology: Applied, vol. 24, p. 34, 2018. https:// doi.org/10.1037/xap0000145

[19] S. K. Carpenter and A. R. Toftness, "The effect of prequestions on learning from video presentations," Journal of Applied Research in Memory and Cognition, vol. 6, pp. 104109, 2017. https://doi.org/10.1016/j.jarmac.2016.07.014

[20] B. Finn and S. K. Tauber, "When confidence is not a signal of knowing: How students' experiences and beliefs about processing fluency can lead to miscalibrated confidence," Educational Psychology Review, vol. 27, pp. 567-586, 2015. https://doi.org/10.1007/s106 $\underline{\text { 48-015-9313-7 }}$

[21] C. K. Lo, C. W. Lie, and K. F. Hew, "Applying "First Principles of Instruction" as a design theory of the flipped classroom: Findings from a collective study of four secondary school subjects," Computers \& Education, vol. 118, pp. 150-165, 2018/03/01/ 2018. https://doi. org/10.1016/j.compedu.2017.12.003

[22] S. Arnab, R. Bhakta, S. K. Merry, M. Smith, K. Star, and M. Duncan, "Competition and Collaboration Using a Social and Gamified Online Learning Platform," in 10th European Conference on Games Based Learning: ECGBL 2016, 2016, p. 19.

[23] M. Urh, G. Vukovic, E. Jereb, and R. Pintar, "The Model for Introduction of Gamification into E-learning in Higher Education," Procedia - Social and Behavioral Sciences, vol. 197, pp. 388-397, 2015/07/25/2015. https://doi.org/10.1016/j.sbspro.2015.07.154

[24] M. Thongmak, "Social network system in classroom: antecedents of Edmodo $\subset$ adoption," Journal of e-Learning and Higher Education, vol. 2013, pp. 1-15, 2013. https://doi.org/ $\underline{10.5171 / 2013.657749}$

[25] H. M. Alfawareh and S. Jusoh, "The Use and Effects of Smartphones in Higher Education," International Journal of Interactive Mobile Technologies (iJIM), vol. 11, pp. 103111, 2017. https://doi.org/10.3991/ijim.v11i6.7453

[26] R. A. Ali and M. R. M. Arshad, "Investigating the Perception of Students Regarding MLearning Concept in Egyptian Schools," iJIM, vol. 11, pp. 112-122, 2017. https://doi.org/ 10.3991/ijim.v11i6.7361

[27] M. Batsila, C. Tsihouridis, and D. Vavougios, "Entering the Web-2 Edmodo World to Support Learning: Tracing Teachers' Opinion After Using it in their Classes," International 
Journal of Emerging Technologies in Learning, vol. 9, 2014. https://doi.org/10.3991/ ijet.v9i1.3018

[28] C. Webel, C. Sheffel, and K. A. Conner, "Flipping instruction in a fifth grade class: A case of an elementary mathematics specialist," Teaching and Teacher Education, vol. 71, pp. 271-282, 2018/04/01/ 2018. https://doi.org/10.1016/j.tate.2018.01.007

[29] T. Endres, S. Carpenter, A. Martin, and A. Renkl, "Enhancing learning by retrieval: Enriching free recall with elaborative prompting," Learning and Instruction, vol. 49, pp. 1320, 2017/06/01/ 2017. https://doi.org/10.1016/j.learninstruc.2016.11.010

[30] K.-y. Lee and Y.-c. Lai, "Facilitating higher-order thinking with the flipped classroom model: a student teacher's experience in a Hong Kong secondary school," Research and Practice in Technology Enhanced Learning, vol. 12, p. 8, 2017. https://doi.org/10.1186/ s41039-017-0048-6

[31] J. Medina, Brain rules: 12 principles for surviving and thriving at work, home, and school: ReadHowYouWant. com, 2011.

[32] P. J. Guo, J. Kim, and R. Rubin, "How video production affects student engagement: An empirical study of mooc videos," in Proceedings of the first ACM conference on Learning@ scale conference, 2014,pp. 41-50. https://doi.org/10.1145/2556325.2566239

[33] J. J. Vazquez and E. P. Chiang, "Flipping out! A case study on how to flip the principles of economics classroom," International Advances in Economic Research, vol. 21, pp. 379390, 2015. https://doi.org/10.1007/s11294-015-9549-5

[34] J. Wang and P. D. Antonenko, "Instructor presence in instructional video: Effects on visual attention, recall, and perceived learning," Computers in Human Behavior, vol. 71, pp. 7989, 2017/06/01/ 2017. https://doi.org/10.1016/j.chb.2017.01.049

[35] H. Yoshida, "Perceived usefulness of" flipped learning" on instructional design for elementary and secondary education: With focus on pre-service teacher education," International Journal of Information and Education Technology, vol. 6, p. 430, 2016. https://doi. org/10.7763/ijiet.2016.v6.727

[36] I. A. E. Spanjers, T. van Gog, and J. J. G. van Merriënboer, "A Theoretical Analysis of How Segmentation of Dynamic Visualizations Optimizes Students' Learning," Educational Psychology Review, vol. 22, pp. 411-423, 2010/12/01 2010. https://doi.org/10.1007/ $\underline{\text { s10648-010-9135-6 }}$

[37] W. Schnotz and R. K. Lowe, "A unified view of learning from animated and static graphics," Learning with animation: Research implications for design, pp. 304-356, 2008.

[38] P. E. Doolittle, L. H. Bryant, and J. R. Chittum, "Effects of degree of segmentation and learner disposition on multimedia learning," British Journal of Educational Technology, vol. 46, pp. 1333-1343, 2015. https://doi.org/10.1111/bjet.12203

[39] R. E. Mayer, G. T. Dow, and S. Mayer, "Multimedia learning in an interactive selfexplaining environment: What works in the design of agent-based microworlds?," Journal of educational psychology, vol. 95, p. 806, 2003. https://doi.org/10.1037/00220663.95.4.806

[40] E. Akdemir and A. Arslan, "Development of Motivation Scale for Teachers," Procedia Social and Behavioral Sciences, vol. 106, pp. 860-864, 2013/12/10/ 2013. https://doi.org/ 10.1016/j.sbspro.2013.12.098

[41] A. Khacharem, I. A. E. Spanjers, B. Zoudji, S. Kalyuga, and H. Ripoll, "Using segmentation to support the learning from animated soccer scenes: An effect of prior knowledge," Psychology of Sport and Exercise, vol. 14, pp. 154-160, 2013/03/01/ 2013. https://doi.org/ 10.1016/j.psychsport.2012.10.006

[42] R. K. Lowe, "Animation and learning: Value for money," in Beyond the comfort zone: Proceedings of the 21st ASCILITE Conference, 2004, pp. 558-561. 
[43] A. Z. M. Ali, "Effects of teacher controlled segmented-animation presentation in facilitating learning," Journal of Educational Multimedia and Hypermedia, vol. 19, pp. 367-378, 2010.

[44] J. Cheon, S. Crooks, and S. Chung, "Does segmenting principle counteract modality principle in instructional animation?," British Journal of Educational Technology, vol. 45, pp. 56-64, 2014. https://doi.org/10.1111/bjet.12021

[45] K. Meyer, T. Rasch, and W. Schnotz, "Effects of animation's speed of presentation on perceptual processing and learning," Learning and Instruction, vol. 20, pp. 136-145, 2010. https://doi.org/10.1016/j.learninstruc.2009.02.016

[46] S. Rahman, "The effects of prequestions on classroom learning," Iowa State University, 2017.

[47] A. Yassine, M. Berrada, A. Tahiri, and D. Chenouni, "A Cross-Platform Mobile Application for Learning Programming Basics," International Journal of Interactive Mobile Technologies (iJIM), vol. 12, pp. 139-151, 2018. https://doi.org/10.3991/ijim.v12i7.9442

[48] F. J. Dowaliby, "Adjunct questions in prose: A question position-by-reading ability interaction," American annals of the deaf, pp. 50-53, 1990. https://doi.org/10.1353/aad.2012. $\underline{0430}$

[49] H. L. Roediger III and J. D. Karpicke, "Test-enhanced learning: Taking memory tests improves long-term retention," Psychological science, vol. 17, pp. 249-255, 2006. https://doi. org/10.1111/j.1467-9280.2006.01693.X

[50] S. K. Carpenter, "Testing enhances the transfer of learning," Current directions in psychological science, vol. 21, pp. 279-283, 2012.

[51] J. Dunlosky, K. A. Rawson, E. J. Marsh, M. J. Nathan, and D. T. Willingham, "Improving students' learning with effective learning techniques: Promising directions from cognitive and educational psychology," Psychological Science in the Public Interest, vol. 14, pp. 458, 2013. https://doi.org/10.1177/1529100612453266

[52] M. A. McDaniel, P. K. Agarwal, B. J. Huelser, K. B. McDermott, and H. L. Roediger III, "Test-enhanced learning in a middle school science classroom: The effects of quiz frequency and placement," Journal of Educational Psychology, vol. 103, p. 399, 2011. https:// doi.org/10.1037/a0021782

[53] L. E. Richland, N. Kornell, and L. S. Kao, "The pretesting effect: Do unsuccessful retrieval attempts enhance learning?," Journal of Experimental Psychology: Applied, vol. 15, p. 243, 2009. https://doi.org/10.1037/a0016496

[54] M. Pressley, R. Tanenbaum, M. A. McDaniel, and E. Wood, "What happens when university students try to answer prequestions that accompany textbook material?," Contemporary Educational Psychology, vol. 15, pp. 27-35, 1990. https://doi.org/10.1016/0361-476x (90) $90003-\mathrm{j}$

[55] S. T. Peverly and R. Wood, "The Effects of Adjunct Questions and Feedback on Improving the Reading Comprehension Skills of Learning-Disabled Adolescents," Contemporary Educational Psychology, vol. 26, pp. 25-43, 2001/01/01/ 2001. https://doi.org/10.1006/ ceps.1999.1025

[56] P. R. Denner and J. P. Rickards, "A developmental comparison of the effects of provided and generated questions on text recall," Contemporary Educational Psychology, vol. 12, pp. 135-146, 1987/04/01/ 1987. https://doi.org/10.1016/s0361-476x(87)80047-4

[57] C. Pesce, C. Crova, L. Cereatti, R. Casella, and M. Bellucci, "Physical activity and mental performance in preadolescents: Effects of acute exercise on free-recall memory," Mental Health and Physical Activity, vol. 2, pp. 16-22, 2009. https://doi.org/10.1016/j.mhpa. $\underline{2009.02 .001}$ 
[58] P. Bhatarah, G. Ward, and L. Tan, "Examining the relationship between free recall and immediate serial recall: The serial nature of recall and the effect of test expectancy," Memory \& Cognition, vol. 36, pp. 20-34, 2008. https://doi.org/10.3758/mc.36.1.20

[59] K. A. Klein, K. M. Addis, and M. J. Kahana, "A comparative analysis of serial and free recall," Memory \& Cognition, vol. 33, pp. 833-839, 2005. https://doi.org/10.3758/bf03 $\underline{193078}$

[60] H. L. Roediger, "The effectiveness of four mnemonics in ordering recall," Journal of Experimental Psychology: Human Learning and Memory, vol. 6, p. 558, 1980. https://doi.org 10.1037//0278-7393.6.5.558

[61] J. R. Anderson, Cognitive psychology and its implications, 6 ed. New York: worth publishing, 2005.

[62] M. J. Peters, M. Hauschildt, S. Moritz, and L. Jelinek, "Impact of emotionality on memory and meta-memory in schizophrenia using video sequences," Journal of Behavior Therapy and Experimental Psychiatry, vol. 44, pp. 77-83, 2013. https://doi.org/10.1016/j.jbtep. 2012.07.003

[63] T. J. Ricker, E. Vergauwe, and N. Cowan, "Decay theory of immediate memory: From Brown (1958) to today (2014)," The Quarterly Journal of Experimental Psychology, vol. 69, pp. 1969-1995, 2016. https://doi.org/10.1080/17470218.2014.914546

[64] J. M. Zacks, N. K. Speer, K. M. Swallow, T. S. Braver, and J. R. Reynolds, "Event perception: a mind-brain perspective," Psychological bulletin, vol. 133, p. 273, 2007. https://doi. org/10.1037/0033-2909.133.2.273

[65] J. Sweller, J. J. Van Merrienboer, and F. G. Paas, "Cognitive architecture and instructional design," Educational psychology review, vol. 10, pp. 251-296, 1998. https://doi.org/10.10 23/a:1022193728205

[66] T. G. Tin, N. A. Atan, M. N. H. M. Said, M. F. Ali, S. Mohd, and M. Z. A. Hamid, "Integrating Animations in Chinese Character Writing Based on Cognitive Theory of Multimedia Learning to Promote Students' Writing Skills," International Journal of Interactive Mobile Technologies (iJIM), vol. 12, pp. 97-111, 2018. https://doi.org/10.3991/ijim.v12 i7.9671

[67] B. S. Hasler, B. Kersten, and J. Sweller, "Learner control, cognitive load and instructional animation," Applied cognitive psychology, vol. 21, pp. 713-729, 2007. https://doi.org/10. 1002/acp. 1345

[68] N. Biard, S. Cojean, and E. Jamet, "Effects of segmentation and pacing on procedural learning by video," Computers in Human Behavior, 2017/12/05/ 2017. https://doi.org/10. 1016/j.chb.2017.12.002

\section{$9 \quad$ Author}

Dr. Marwa Zaki Tawfiq Zaki, associate Professor, Instructional technology Department, College of Specific Education, Ain Shams University, Cairo, Egypt, Research Interests in the field of E-Learning, Mobile Games, 3D environments, Augmented Reality. (e-mail: dr.marwa.zaki@sedu.asu.edu.eg; drmarwaa_doc@hotmail. com)

Article submitted 2019-04-06. Resubmitted 2019-05-20. Final acceptance 2019-05-20. Final version published as submitted by the authors. 